Research Article

\title{
Prefailure Deformation of Nailed Deep Excavations under Surcharge by Centrifuge Model Test
}

\author{
S. Mohammad. Shoari Shoar (D), Ali A. Heshmati ${ }^{D}$, and Hossein Salehzadeh \\ Faculty of Civil Engineering, Iran University of Science and Technology, Tehran 1684613114, Iran \\ Correspondence should be addressed to Ali A. Heshmati; heshmati@iust.ac.ir
}

Received 22 February 2021; Revised 8 August 2021; Accepted 14 August 2021; Published 25 August 2021

Academic Editor: Jia-wen Zhou

Copyright (c) 2021 S. Mohammad. Shoari Shoar et al. This is an open access article distributed under the Creative Commons Attribution License, which permits unrestricted use, distribution, and reproduction in any medium, provided the original work is properly cited.

\begin{abstract}
To study prefailure deformations in nailed deep vertical excavations under various surcharges, four centrifuge tests were used to explain the lateral deformation of facing, the fracture mechanism of cement facing, and the settlement profile of the ground surface. The soil used in this research was Firoozkooh sand No. 161. Both surcharge applying and excavation were performed at $40 \mathrm{~g}$ acceleration. The depth of the excavation was $30 \mathrm{~cm}$, the length of the nail varied from $\mathrm{H} / 3$ to $2 \mathrm{H} / 3$ (H: excavation depth), and the nails were installed horizontally. The nails were made of brass pipes and then sand coated. The results showed that the effect of surcharge on the lateral deformation of the facing as well as the fracture mechanism of facing is obvious. Also, it was seen that the ground settlement profile is two-line or three-line at the moment of facing fracture and is affected by surcharge.
\end{abstract}

\section{Introduction}

Excavation in urban areas has two main features: first, due to the high value of land, excavation is done vertically, and secondly, excavation is always carried out next to an adjacent building, which applies a surcharge to the stabilizing excavation. In this research, the deformations of the nailed excavations in the vicinity of surcharge have been investigated and examined the effect of surcharge amount.

A few full-scale tests have been carried on nailed walls. Clouterre [1] stabilized three walls 6 to $7 \mathrm{~m}$ high by nailing and investigated lateral deformations and soil settlement behind the wall in a failure state. Guller and Bozkourt [2] studied the effect of nail angle on the nailed wall performance. There was no surcharge in these two studies. To avoid the high cost of full-scale tests and their nonrepetition, centrifuge tests or numerical analysis can be used. Joel and Pedley, Shiu and Chang, Wei and Cheng, Singh and Babu, and Hajialilu-Bonab and Razavi [3-7] showed that the bending stiffness of nail is insignificant, and Singh and Babu [6] showed that the bending stiffness of the nail has little effect on the horizontal displacement of the wall. Fan and Luo, Rotte and Viswa, and Askari and Gholami [8-10] reported that, for vertical excavations, the horizontal nail has the best performance. Shiu and Chang [5] also showed that the stability of the excavation decreases with increasing the nail angle to the horizon. Besides, Lin et al. [11] reported that maximum load is mobilized in a horizontal nail. Babu et al. [12] and Shiu and Chang [5] showed that a $75 \mathrm{~mm}$ thick facing is sufficient, and greater thickness is ineffective in facing lateral deformation (Jayanandan and Chandarakaran [13]). Jayanandan and Chandarakaran [13] and Ghareh [14] reported that, as the cohesion and internal friction angle of soil increases, the lateral deformation of nailed excavations decreases; also, Ghareh [14] found that the higher the surcharge, the greater the horizontal deformation of the excavation. Halabian et al. [15] observed that the nail angle to the horizon, the nail length, and the soil characteristics affect the lateral soil pressure applied to the facing. Sabermahani et al. [16] investigated the surcharge effect on lateral deformation and soil settlement behind the facing. Razavi and Hajialilu-Bonab [17] found that soils with high elasticity experienced uniform settlement and soils with low elasticity experienced large differential settlement; also, if the higher nails are placed at the top, the excavation will experience a uniform settlement. Wei and Cheng [7] showed that nail 
head stiffness has little effect on the safety factor and slope failure mechanism. Tei et al. [18] observed that the maximum lateral deformation of the facing occurred at the top of the wall, and the location of force effect was slightly higher than H/3. Hajialilu-Bonab and Razavi, Rotte and Viswa, and Shiu and Cheng $[3,5,10]$ showed that if longer nails are placed at the top, it controls the deformation of the excavation.

\section{Centrifuge Models}

2.1. Generals. The centrifuge utilized in this research belongs to the faculty of engineering of Tehran University. This centrifuge is of arm type with an arm radius of 2.7 meters. Also, it possesses a floating platform that can carry $850 \mathrm{~kg}$ in an acceleration of $130 \mathrm{~g}$. The box used for the model has a length of $80 \mathrm{~cm}$, a width of $40 \mathrm{~cm}$, and a height of $50 \mathrm{cen}-$ timeters. To monitor the behaviour of the excavation during the test, transparent plexiglass with a thickness of $4 \mathrm{~cm}$ was used on the front face of the box, and four points on the plexiglass were defined as fixed points in a rectangular grid to enable an image processing analysis. A Canon G7 camera with a resolution of $5 \mathrm{MB}$ was placed in front of the model to allow imaging during the test. Also, to increase the quality of the images, an LED strip lamp at the top of the box is used to illuminate the model front space.

2.2. Scaling Considerations for Nailed Excavations. In the present study, the target acceleration is considered to be $40 \mathrm{~g}$, which models a prototype excavation $12 \mathrm{~m}$ deep. Because in professional work for deeper excavations that are under surcharge, nailing is usually not a suitable method to reduce deformations and anchoring method is used instead. The centrifuge scaling factor proposed by Kutter [19] is presented in Table 1.

\subsection{Model Materials}

2.3.1. Soil. The soil used in the present study was Firoozkooh sand No. 161. The soil water content is $6 \%$, maximum dry weight density is $15.38 \mathrm{kN} / \mathrm{m}^{3}$, and soil apparent cohesion and internal friction angle based on the direct shear test were $17.2 \mathrm{kPa}$ and 30.4 degrees, respectively. Uniformity coefficient, specific gravity, and mean particle size $\left(D_{50}\right)$ were 1.87 , 2.65 , and $0.27 \mathrm{~mm}$, respectively, and the shape of the grains was angular. Since soil density was not one of the studied variables on excavation behaviour, a moderate relative density (50\%) was considered for all soil models. The temping method was used to compact the soil by using soil mechanical relations; first, the void ratio equal to the relative density of $50 \%$ and then the corresponding wet unit weight were obtained, and finally, the soil weight that should fit in the volume of a $2.5 \mathrm{~cm}$ layer of soil was calculated. It is classified as poorly graded sand, SP, according to the Unified Soil Classification System (USCS). The soil grading curve is shown in Figure 1.
TABLe 1: Centrifuge scaling factors by Kutter [19].

\begin{tabular}{lcc}
\hline Quantity & Full scale & Model \\
\hline Length & 1 & $1 / n$ \\
Acceleration & 1 & $n$ \\
Area & 1 & $1 / n^{2}$ \\
Volume & 1 & $1 / n^{3}$ \\
Mass & 1 & $1 / n^{3}$ \\
Force & 1 & $1 / n^{2}$ \\
Stress & 1 & 1 \\
Strain & 1 & 1 \\
Displacement & 1 & $1 / n$ \\
Axial stiffness (EA) & 1 & $1 / n^{2}$ \\
Axial stiffness (EA/L) & 1 & $1 / n$ \\
Bending stiffness (EI) & 1 & $1 / n^{4}$ \\
Bending stiffness (EI/L) & 1 & $1 / n^{3}$ \\
Density & 1 & 1 \\
\hline
\end{tabular}

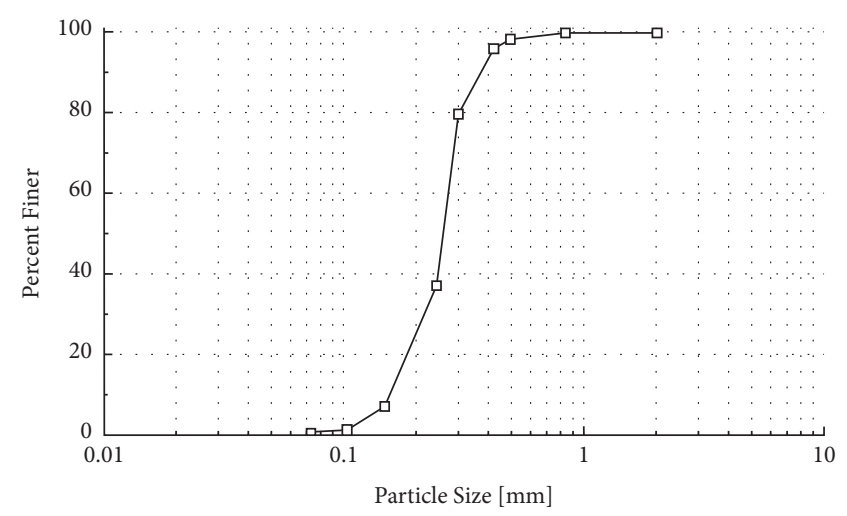

FIgURE 1: Grading curve of Firoozkooh sand No. 161.

2.3.2. Nails. In this study, brass pipes that are sand coated were used as the nail in the model. The brass pipes' inner and outer diameters were 3.4 and $4 \mathrm{~mm}$, respectively, which shows a prototype nail with a $14 \mathrm{~cm}$ diameter borehole filled by grout and reinforced by a $40 \mathrm{~mm}$ bar. Since in professional work, the diameter of the boreholes in nailing is usually 100 to $150 \mathrm{~mm}$, so in the present study, the borehole diameter was considered to be $140 \mathrm{~mm}$. Figure 2 indicates the specifications of the prototype and the model nails. In the model nail, the brass pipe head is threaded so that it was possible to install the hexagonal M5 nut and washer as the nail head. According to Joel and Padley, Shiu and Chang, Singh and Babu, Wei and Cheng, and Hajialilu-Bonab and Razavi [3-7], to model the nails, their axial stiffness has been used. Since the prototype nail is a combination of grout and bar, equation (1) is used to calculate the modulus of elasticity:

$$
E_{e q} A_{\text {total }}=E_{s} A_{s}+E_{g} A_{g}
$$

where $E_{e q}$ is the equivalent elasticity modulus of the nail, $A_{\text {total }}$ is the total cross-section area of the nail $\left(154 \mathrm{~cm}^{2}\right), E_{s}$ is the elasticity modulus of steel $\left(2.1^{*} 10^{6} \mathrm{~kg} / \mathrm{cm}^{2}\right), A_{s}$ is the cross-section of a bar $\left(12.6 \mathrm{~cm}^{2}\right), E_{g}$ is elasticity modulus of the grout $\left(2 * 10^{5} \mathrm{~kg} / \mathrm{cm}^{2}\right)$, and $A_{g}$ is the cross-section area of 


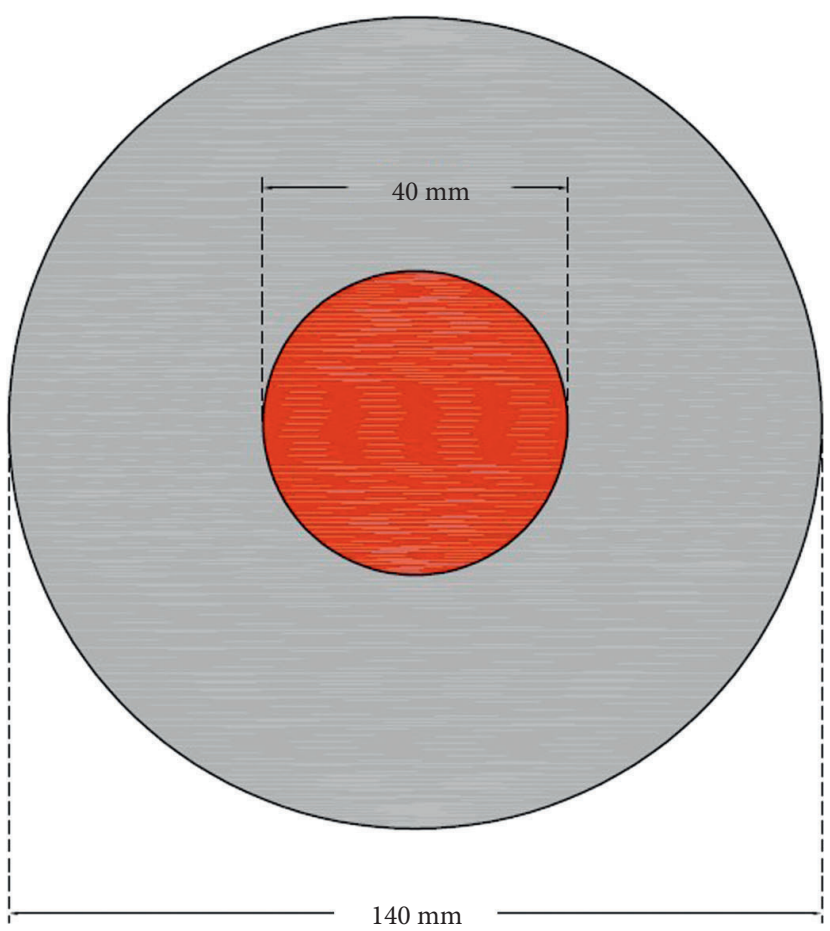

(a)

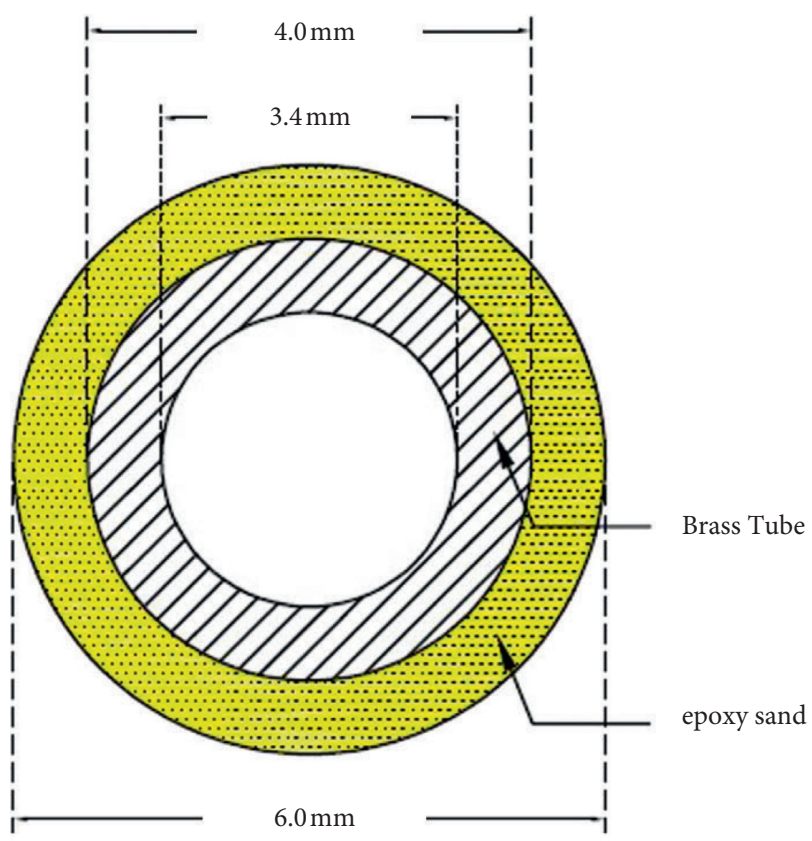

(b)

FIgure 2: Nail dimensions. (a) Prototype nail. (b) Model nail.

the grout $\left(A_{g}=A_{\text {total }}-A_{s}, 141 \mathrm{~cm}^{2}\right)$. By calculating the elasticity modulus of the prototype nail and using equation (2), the model nail dimensions are calculated:

$$
\left(\frac{E A}{S_{h}}\right)_{p}=n\left(\frac{E A}{S_{h}}\right)_{m}
$$

where $E_{m}$ is the brass elasticity modulus (100 GPa), $\left(S_{h}\right)_{m}$ is the horizontal distance of the model nails $(5 \mathrm{~cm})$, and $\left(S_{h}\right)_{p}$ is the horizontal distance of the prototype nails $(2 \mathrm{~m})$. Also, a scaling factor of 40 was considered. By placing in equation (2), the cross-section area of the model nail is $3.41 \mathrm{~mm}^{2}$, which is equivalent to a pipe with external and internal diameters of 4 and $3.4 \mathrm{~mm}$, respectively. Figure 3 shows the nail's location and the horizontal and vertical nails distance from each other and the edge of the facing in tests 2, 3, and 4. According to FHWA and in professional work, it is recommended that the maximum distance between the horizontal and vertical nails be 2 meters. Therefore, in the present study, the maximum acceptable distance of the regulations has been used.

2.3.3. Facing. The facing used in past research was made of tensile elements such as aluminium-polyester plate [10], PVC plate [16], aluminium plate [20], and Perspex [18, 21]. Since shotcrete is a compressive element in the prototype facing, a cement facing with a thickness of $5 \mathrm{~mm}$, a length of $40 \mathrm{~cm}$, and a height of $30 \mathrm{~cm}$ was used which was reinforced with steel lace. The steel lace used in the model was $0.25 \mathrm{~mm}$ thick with a 2 by $2 \mathrm{~mm}$ mesh grid, equivalent to a prototype mesh with a $10 \mathrm{~mm}$ bar and an 8 by $8 \mathrm{~cm}$ mesh. To implement the facing, first, a plastic cover plate is glued inside a steel mould with a length and height of 40 and $30 \mathrm{~cm}$ and a thickness of $5 \mathrm{~mm}$, respectively. Then, a steel lace with suitable dimensions is pasted on the plastic cover inside the mould. Finally, the previously prepared 1-to-1 cement grout is poured into the mould, and it hardens after a while (Figure 4). Then, the cement facing is hanged out from the mould by removing the plastic cover. To install the nails by a hand drill, a hole grid with a diameter of $5 \mathrm{~mm}$ is created in the facing so that the threaded head of the nail comes out of the facing; in this way, it will be possible to construct the nail head. Based on ACI 318-14 and using equation (3), the elasticity modulus of cement grout was calculated:

$$
E=4700 \sqrt{f_{c}} .
$$

The 28-day compressive strength of the prototype and model facing is 21 and $5.5 \mathrm{MPa}$, respectively. Then, the prototype facing thickness is achieved by the following equation:

$$
(E I)_{P}=n_{4}(E I)_{m} \longrightarrow t_{P}=n t_{m} \sqrt[3]{\frac{E_{m}}{E_{P}}} .
$$

Since the model facing thickness is $5 \mathrm{~mm}$ and assuming $n=40$, the prototype facing thickness is obtained to be $159.97 \mathrm{~mm}$.

2.4. Model Preparation. On the left side of the box, the soil model was built with a length of 50 , a width of 40 , and a height of $35 \mathrm{~cm}$. First, two $2.5 \mathrm{~cm}$ layers of the heel were 


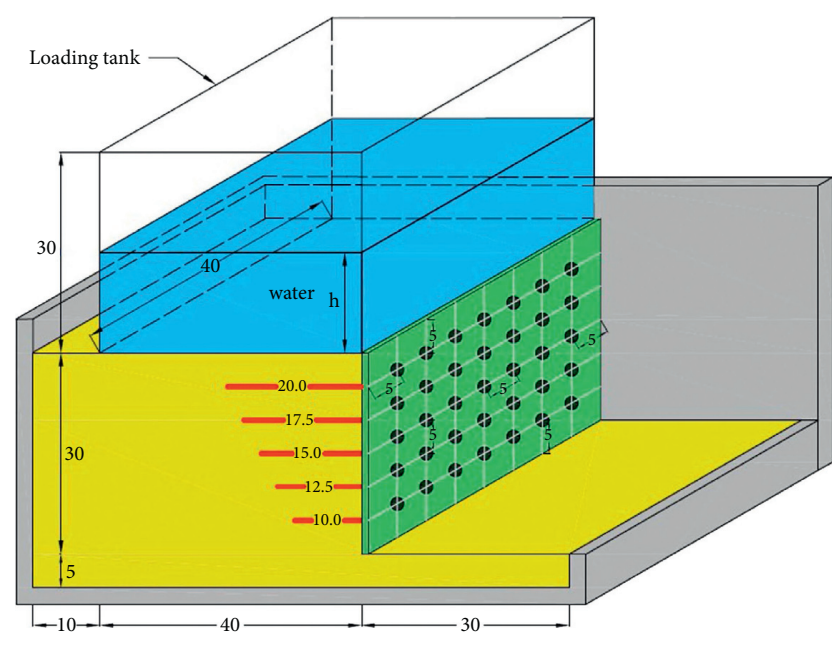

FIgURE 3: Schematic cross section of nailed excavations under surcharge (all dimensions are in $\mathrm{cm}$ ).

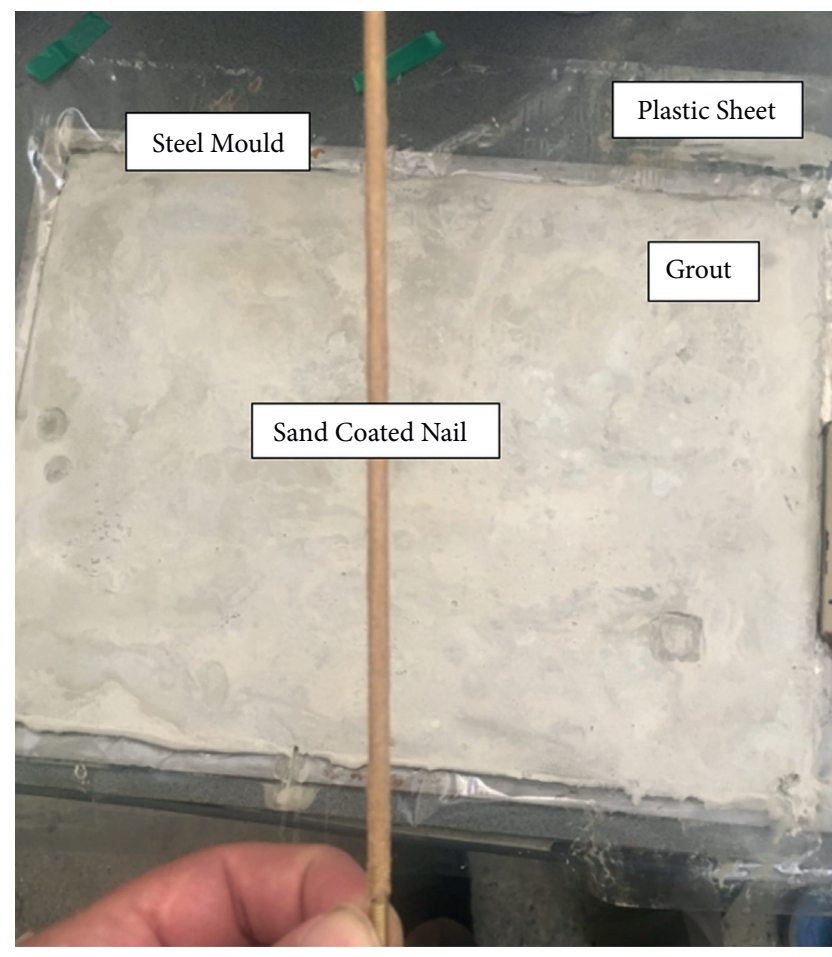

FIgURE 4: Sand-coated nail and facing construction.

constructed along the entire length of the box. Then, on the right side of the box, six compressed foams with a thickness of $5 \mathrm{~cm}$ were placed so that the construction of a soil model without lateral deformation may be possible. In the next step, the facing was placed in its place. Then, the construction of the soil model was initiated by implementing the first and second layers with a thickness of $2.5 \mathrm{~cm}$, and then, the first-row nails were placed so that their threaded head penetrated the foams. After constructing each layer, in front of the model, in contact with plexiglass, and also behind the model, along with the layer, silicone oil has been used to reduce friction. Next, the third and fourth layers were compacted, and then, the second-row nails were placed. The same process continued until the end of model construction. Finally, a model with 12 layers of $2.5 \mathrm{~cm}$ with a density of $50 \%$ was made. The final height of the model was $30 \mathrm{~cm}$, which simulated a prototype deep excavation with a depth of 12 meters at target acceleration. After completing the model, the box was transferred into the centrifuge chamber using a crane and placed in the centrifuge basket. Then, the foams were removed from the box, and the M5 nut and washer were installed on the threaded head of each nail to play the role of the nail head. Figure 5(a) represents the front view of the facing after installing the washers and nuts. Also, in Figure 5(b), the model view can be seen after placing the loading tank. Eventually, a transparent and flexible membrane was put in place of the foams and filled with colored water to fill the space between the soil model and the box. By water draining from the membrane at the target acceleration, excavation is simulated.

2.5. Loading Set-Up. To apply surcharge at target acceleration $(40 \mathrm{~g})$, an open aluminium tank with a thickness of $2 \mathrm{~mm}$ and a weight of $2.7 \mathrm{~kg}$ with dimensions of 40 by $40 \mathrm{~cm}$ and a height of $35 \mathrm{~cm}$ was placed on the soil model to accommodate the water as surcharge at the target acceleration. The aluminium tank base is flexible, which simulates a flexible foundation, thus making it possible to transfer uniform pressure to the soil model. Then, a large steel tank was installed on a steel stool. Finally, the stool that carried the steel tank was placed on the box. Using a solenoid valve located under the steel water tank and a thin perforated hose connected to the solenoid valve on one side and extending to the bottom of the loading tank on the other side, it was possible to transfer water as a surcharge to the loading tank. This was carried out through a key in the control room. After the acceleration reached $40 \mathrm{~g}$, the water was transferred from the steel tank to the loading tank by opening the solenoid valve. To monitor the accuracy of the water transfer process into the loading tank, two simultaneous methods were used. First, a small camera was used under the steel tank and above the loading tank so that the water filling process inside the loading tank could be exactly visible. Moreover, by adding ink into the water and using a piezometer next to the aluminium tank and a camera installed in front of the piezometer, water transfer to the loading tank was monitored. By filling the loading tank with water, applying the surcharge to the soil model was simulated. In this study, several surcharges were used, so the height of water in the loading tank was different. Figure 6 illustrates a centrifuge set-up box.

2.6. Excavation Set-Up. Next to the box, there is a drainage tank to transfer the drained water from the membrane during the test, connected to the membrane through a solenoid valve and a small hole at the bottom of the box (Figure 7). After the loading tank was filled with water and surcharge was applied, by opening the second solenoid valve, the water inside the membrane was transferred to the drainage tank. To monitor the water drainage from the 

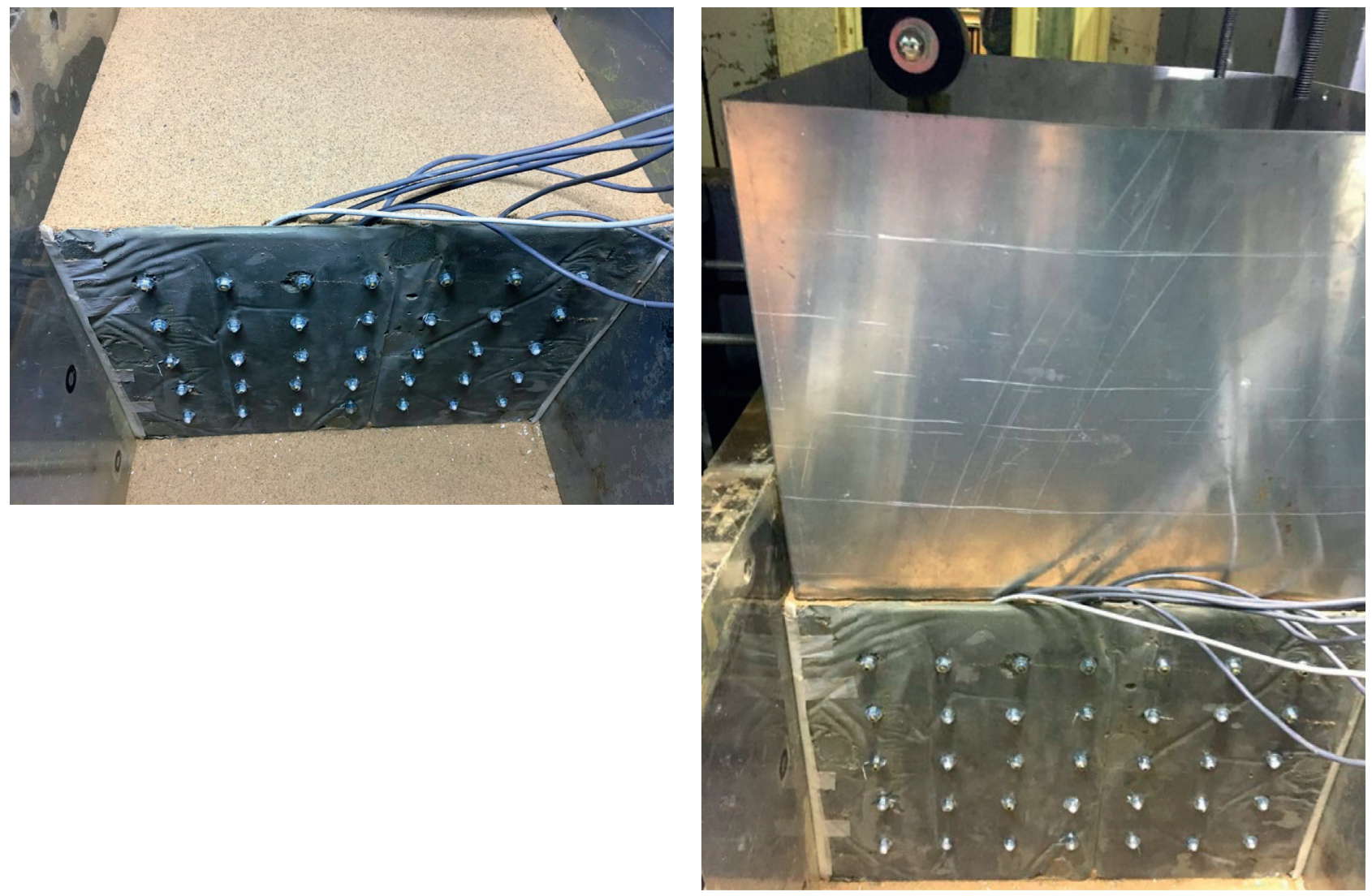

(a)

(b)

Figure 5: (a) Front view of the facing after installing the nuts. (b) Cross section view of the soil model after placing the loading tank.

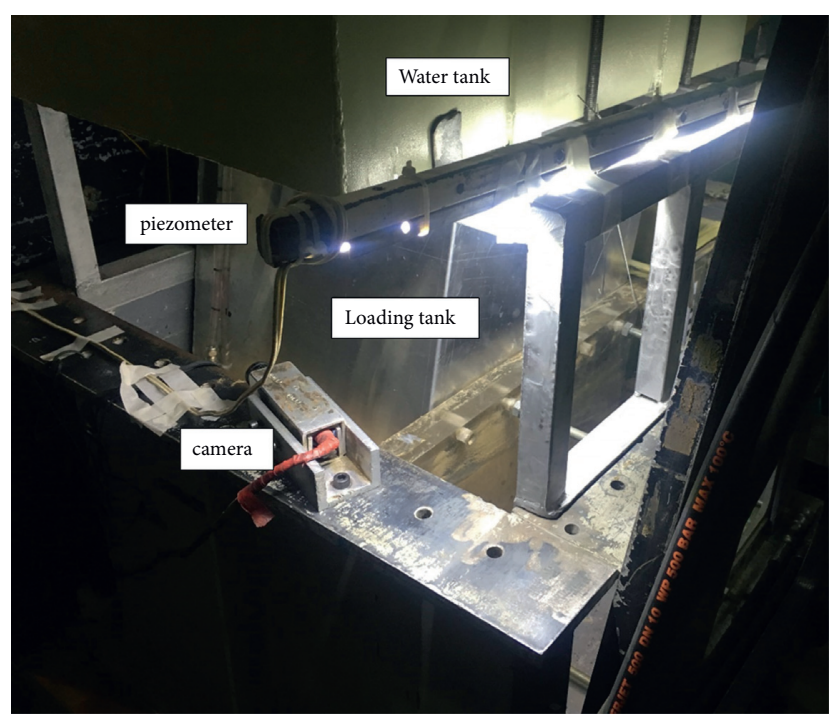

Figure 6: Centrifuge set-up box.

membrane, the ink was poured into the water so that the water level inside the membrane could be easily detected. The camera, placed directly in front of the model and plexiglass, monitored the water level inside the membrane. Earlier, Tei et al., Jacobsz, and Sabermahani et al. [16, 18, 22] used the idea of water drainage to simulate excavation.
2.7. Test Program. In this study, four tests were used. In the first test, the soil model had no nailing and surcharge, but the other models were subjected to a surcharge and were nailed. Three different surcharges of 40,70 , and $100 \mathrm{kPa}$ were used to simulate 4,7 , and 10 story buildings. If the number of building floors is more and more surcharge is applied to the excavation, anchoring method is used instead of nailing. Because the purpose was to investigate the excavation deformation in conditions close to failure, short nails were used, which leads to a safety factor of less than one. According to Hajialilu-Bonab and Razavi, Rotte and Viswa, and Shiu and Cheng $[3,5,10]$, longer nails at the top of the excavation reduce deformations. For this purpose, in this study, shorter nails at the bottom and longer nails at the top of the excavation were used. According to Figure 3, five rows of nails were used with lengths of $10,12.5,15,17.5$, and $20 \mathrm{~cm}$ (from bottom to top, respectively). Details of centrifuge model tests are presented in Table 2.

\section{Analysis and Interpretation of Test Results}

3.1. General. The effect of surcharge amount on the facing lateral deformation, ground surface settlement profile, and cement facing fracture mechanism in the nailed deep vertical excavations was evaluated. To detect deformations, colored silica aggregates with grains of 5 to $8 \mathrm{~mm}$ were used so that, after compacting each soil layer, the silica aggregates were 


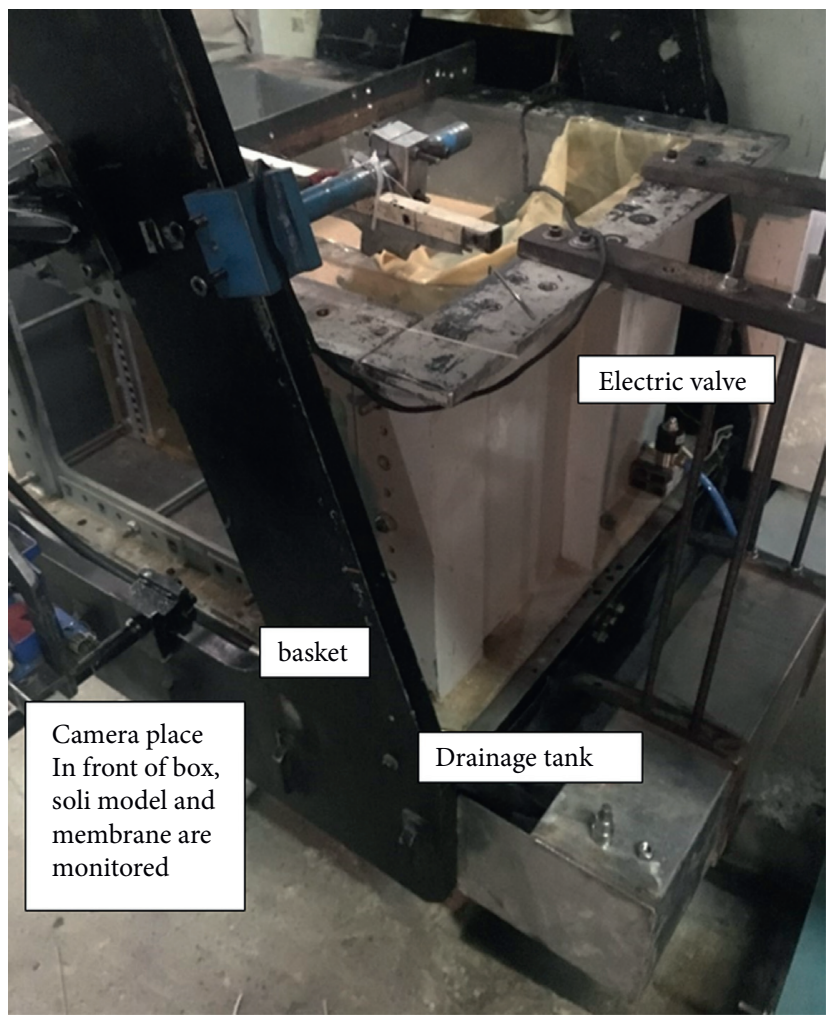

FIGURE 7: Excavation set-up.

TABLE 2: Details of centrifuge model tests.

\begin{tabular}{|c|c|c|c|c|c|c|c|c|}
\hline \multirow[t]{2}{*}{ Test no. } & \multirow[t]{2}{*}{ Surcharge $(\mathrm{kPa})$} & \multicolumn{2}{|c|}{$\begin{array}{l}\text { Excavation } \\
\text { parameters }\end{array}$} & \multicolumn{5}{|c|}{ Nail parameters } \\
\hline & & $\beta$ & $\mathrm{H}(\mathrm{mm})$ & $\alpha$ & Nailing & Number of nails & $S_{h} / \mathrm{H}$ & $S_{v} / \mathrm{H}$ \\
\hline 1 & - & 90 & 300 & 0 & - & 0 & - & - \\
\hline 2 & 100 & 90 & 300 & 0 & Yes & 35 & 0.167 & 0.167 \\
\hline 3 & 70 & 90 & 300 & 0 & Yes & 35 & 0.167 & 0.167 \\
\hline 4 & 40 & 90 & 300 & 0 & Yes & 35 & 0.167 & 0.167 \\
\hline
\end{tabular}

$\beta$ denotes excavation angle, $H$ denotes excavation depth, $\alpha$ denotes angle of the nail to the horizon, $S_{h}$ denotes horizontal distance of the nails, and $S_{v}$ denotes vertical distance of the nails.

placed at a distance of about 3 to $4 \mathrm{~cm}$ close to each other. The arrangement of the measuring points did not need to be the same for all models because by image processing, the condition of each model was checked before excavation and after the facing was broken, and its deformations were recorded. ImageJ software was also used to analyze image processing. Figure 8 shows the soil model made with the silica aggregates used to analyze the image processing during water drainage within the membrane.

Excavation is modelled by water drainage from the membrane. The more the water drains, the further the excavation goes. In tests 2 to 4 , in which the excavations have been nailed, as more water drains the membrane, the facing gradually begins to move under soil pressure. The more water drains the membrane, the greater the facing deformation, which ultimately approaches the failure condition, and the facing fractures. The lateral deformation profile of facing and ground surface settlement can be estimated just before the facing fracture. Furthermore, the facing fracture mechanism can be investigated.

3.2. Facing Lateral Deformation on the Fracture Threshold. Facing deformation just before the fracture includes a combination of transitional, rotational, and bulging modes (Figure 9 shows the two modes of transition and rotation to simplify). The higher the surcharge, the larger the facing rotation at depths close to the critical depth on the facing fracture threshold. The development of facing lateral deformation from the moment of starting the excavation until the facing fracture threshold is shown in Figure 10. It can be seen that when the excavation depth approaches the critical depth, the lateral deformation rate of the excavation increases (the critical depth $\left(h_{\mathrm{cr}}\right)$ is the depth of water in the membrane at the exact time of facing fracture). It is also observed for all models, the maximum and minimum lateral 


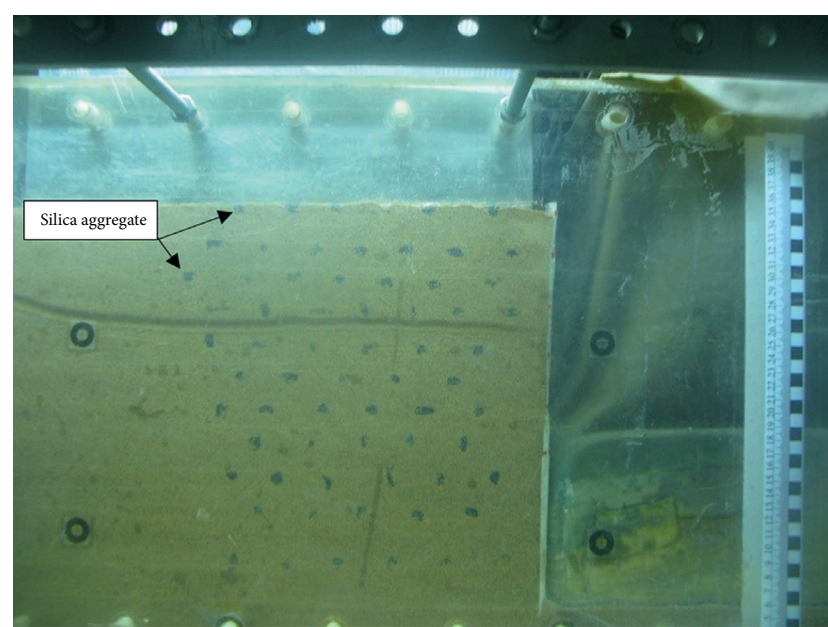

FIgURE 8: Silica aggregates used in the models.

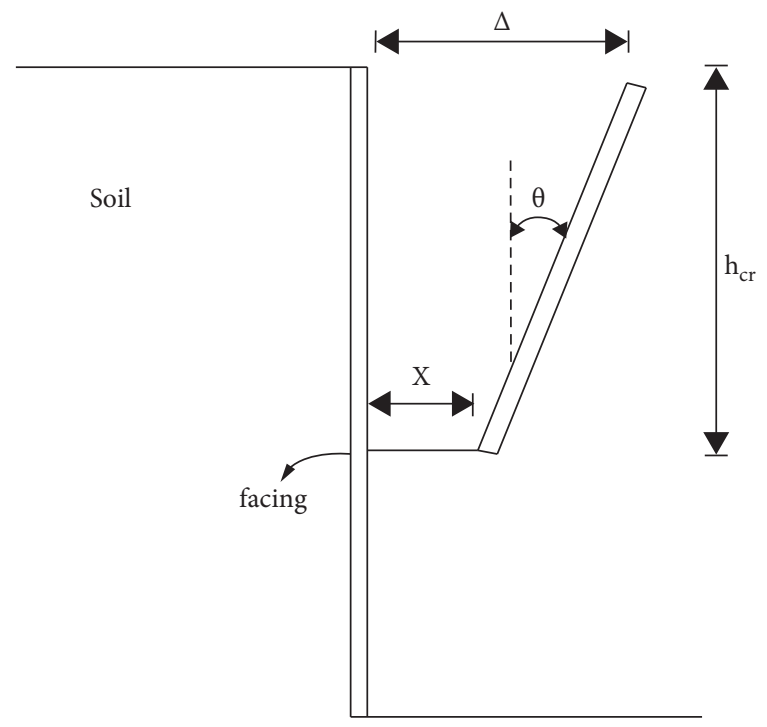

Figure 9: Facing deformation modes.

displacement occurred at the top and bottom of the excavation, respectively, which is consistent with the results of Tei et al. [18] and Gassler et al. [23], but Sabermahani et al. [16] found that the lateral deformation profile of the facing is a function of surcharge so that, for high and low surcharges, the maximum lateral deformation is seen at the top and in the middle of the excavation, respectively. Halabian et al. [15] revealed that the lateral deformation of excavation includes three modes of transition, bulging, and rotation so that the deformation of the top of the excavation is more than its bottom. Also, for the horizontal nails, they found that the lateral deformation at the top of the wall was nearly 2 times than that at its bottom. Jacobsz [22] showed that the lateral deformation at the top of the wall is at least 3 times greater than the middle of the wall. But Zhang et al. [20] observed the maximum lateral deformation occur in the lower third in the nailed clay slopes.

Since to achieve failure conditions the safety factor of three nailed models was considered smaller than one, the facing fracture occurred before water was completely drained from the membrane. Therefore, the critical depth in each test is different so that for surcharges of 100,70 , and $40 \mathrm{kPa}$, they are $12.9,18.5$, and $21.7 \mathrm{~cm}$, respectively. It can be seen that the critical depth decreases with increasing surcharge.

$\delta_{i}$ is the facing lateral deformation at different stages of excavation so that $\delta_{1}, \delta_{2}$, and $\delta_{3}$ are the facing lateral deformation when the excavation depth reaches $5 \mathrm{~cm}, 10 \mathrm{~cm}$, and $15 \mathrm{~cm}$, respectively. Also, $\Delta$ is the total lateral deformation of facing at the facing fracture threshold. According to Figure 11, there is a direct relationship between the surcharge and facing lateral deformation rate so that the higher the surcharge, the more lateral deformation increases. This issue is more pronounced at depths close to the critical depth. Clouterre [1] employed three full-scale walls to show that lateral deformation and settlement at the top of the facing are approximately equal. But it should be noted that surcharge can increase lateral deformation compared to settlement so that, in the present study for low $(40 \mathrm{kPa})$ and high $(100 \mathrm{kPa})$ surcharge, the lateral deformation above the facing is two and six times the settlement, respectively. It seems that, with increasing surcharge, the ratio of lateral deformation of the facing to the settlement increases.

It is also possible to examine the ratio of total lateral deformation $(\Delta)$ variations due to transitional, rotational, and bulging movements of the facing to critical depth $\left(h_{\mathrm{cr}}\right)$ for different surcharges at the moment of facing fracture (Figure 12). This ratio $\left(\Delta / h_{\mathrm{cr}}\right)$ is called the total rotation of the excavation at failure threshold or "failure rotation threshold." At a low surcharge, the failure rotation threshold is lower, and at a medium and high surcharge is higher, at the same time, it can be seen that, during the excavation, the total lateral deformation of the excavation $(\Delta)$ for facing fracture is $5 \%$ of the critical depth for a low surcharge and $9.2 \%$ and $11.8 \%$ of the critical depth for medium and high surcharges, respectively. In other words, the required $\left(\Delta / h_{\mathrm{cr}}\right)$ to achieve the failure state at a medium surcharge is nearly doubled, and for a high surcharge, more than twice the amount required for a low surcharge is estimated. This issue proves that the higher the surcharge, the more flexible the excavation behaves, and the failure rotation threshold increases. On the contrary, it can be seen that the facing rotation is the highest at a high surcharge and the lowest at a low surcharge (Figure 12).

The facing net rotation, as shown in Figure 13, is directly related to the surcharge. For the $40 \mathrm{kPa}$ surcharge, the facing net rotation at the moment of facing fracture is 0.032 radians and is the minimum, and the maximum net rotation is for the $100 \mathrm{kPa}$ surcharge, which is 0.071 radians. For the surcharge of $70 \mathrm{kPa}$, this value is 0.063 radians. Therefore, the minimum and maximum net rotation that causes the facing fracture is in the range of 0.032 to 0.071 radians. Consequently, the maximum facing rotation for the medium surcharge is almost two times, and for the high surcharge is more than twice that of the low surcharge.

Another mode of facing movement is the transitional mode. Increasing the surcharge increases the transitional motion at the bottom of the facing (at the critical depth $(x)$ ), 


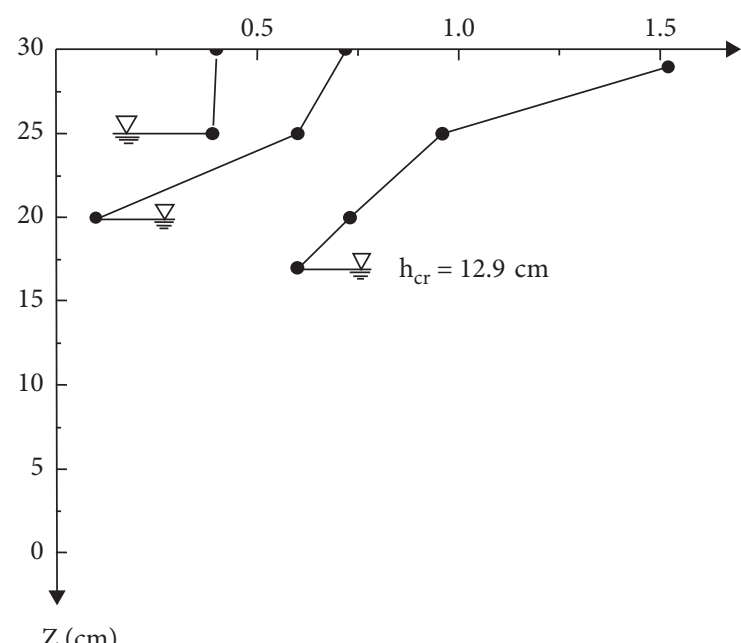

(a)

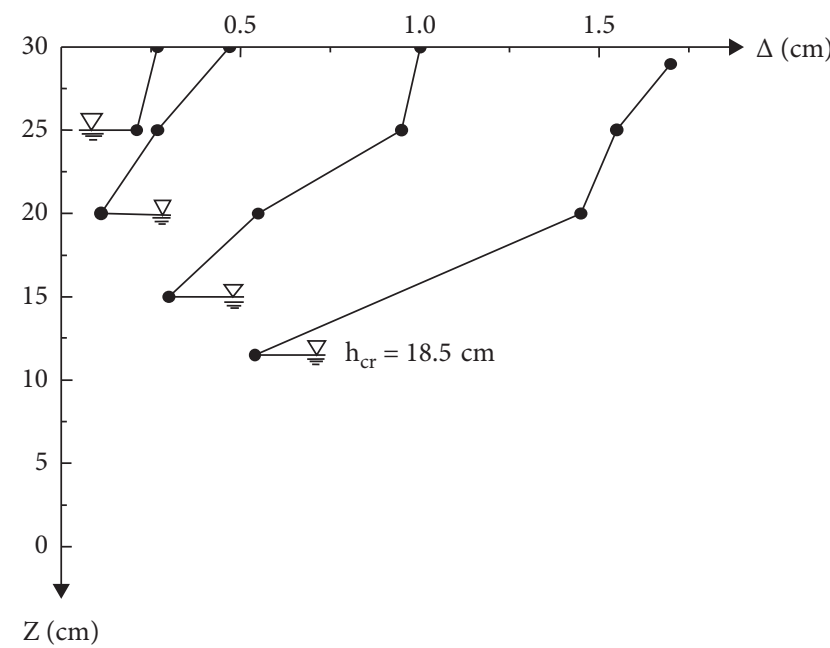

(b)

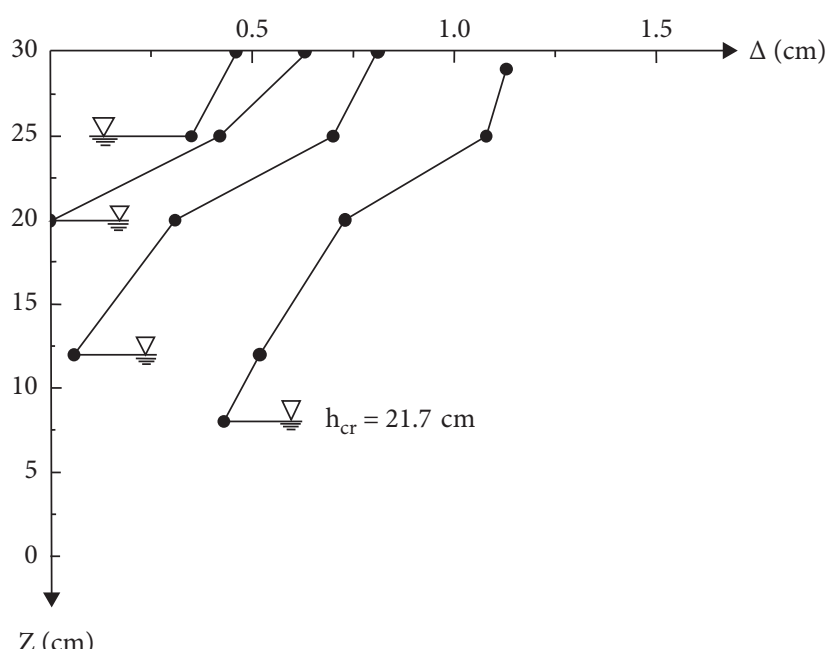

(c)

Figure 10: Lateral deformation development of facing from the starting of excavation until the facing fracture threshold. (a) $100 \mathrm{kPa}$ surcharge. (b) $70 \mathrm{kPa}$ surcharge. (c) $40 \mathrm{kPa}$ surcharge.

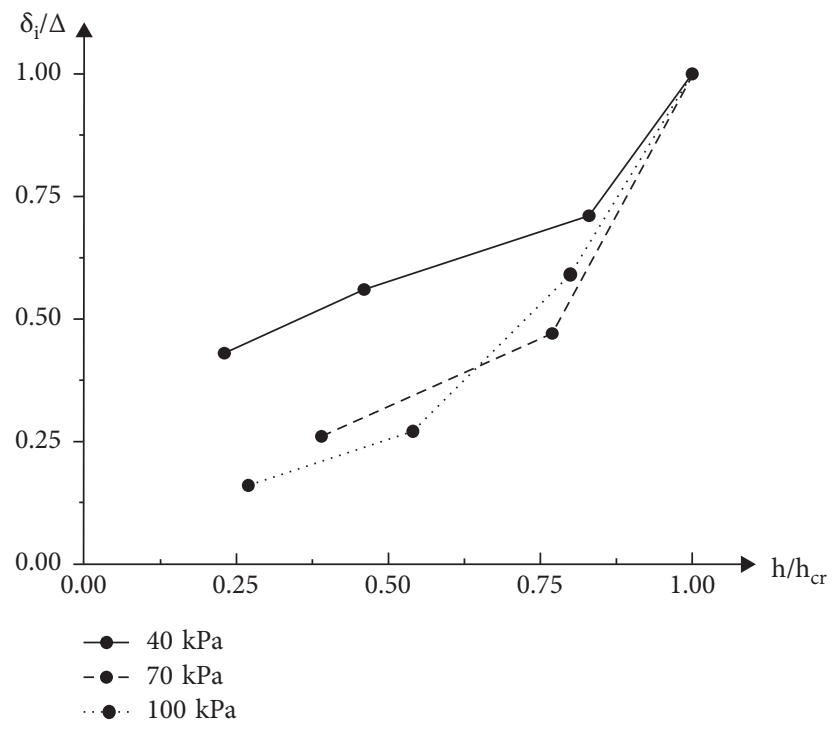

FIgURE 11: Variations of $\delta_{i} / \Delta$ versus $h / h_{\text {cr }}$ for different surcharges. 


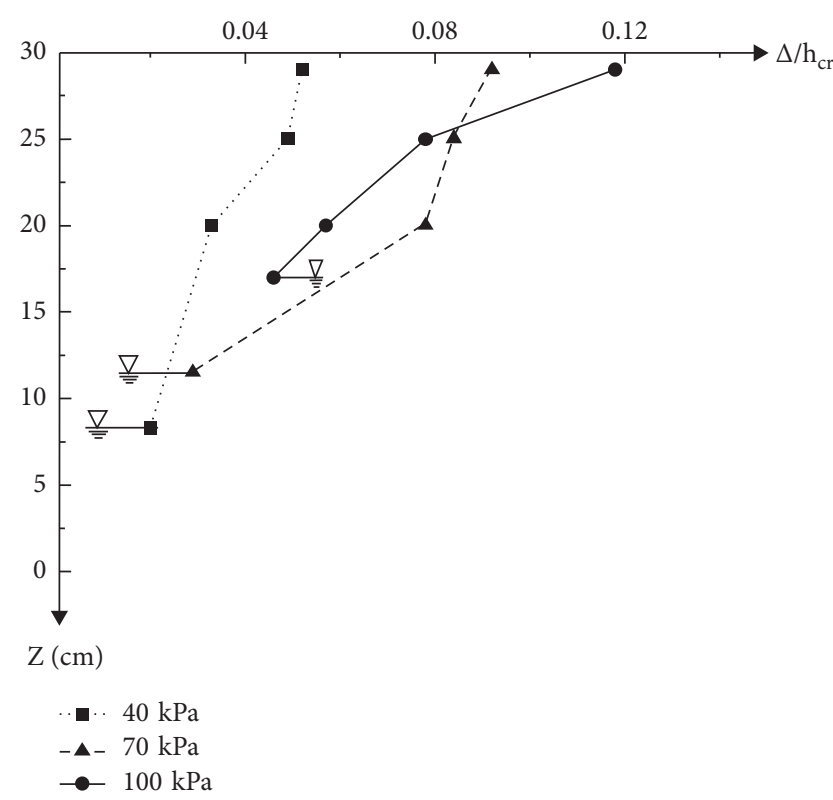

Figure 12: The variations of $\Delta / h_{\mathrm{cr}}$ in depth for different surcharges.

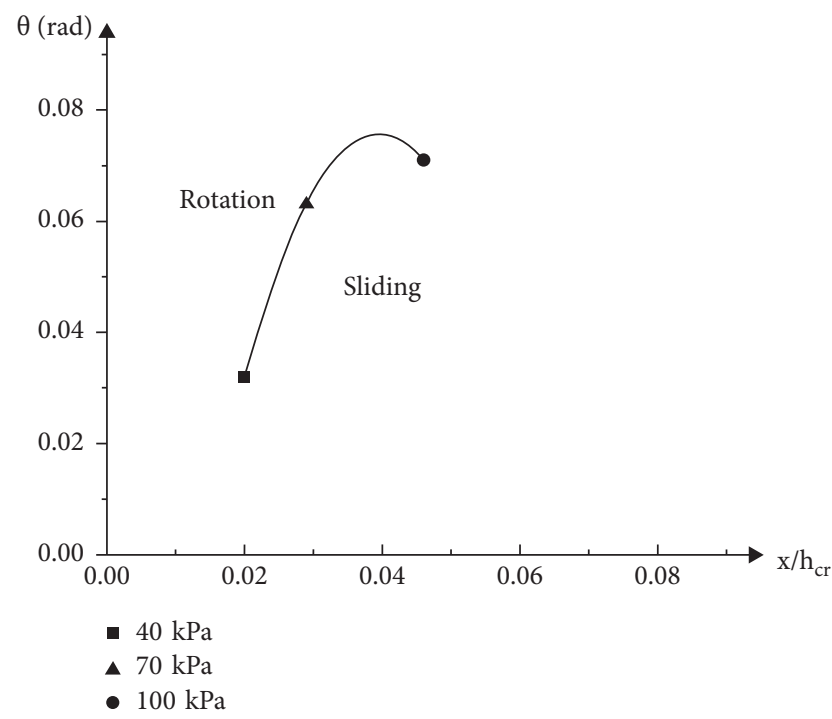

Figure 13: Excavation net rotation variations versus normalized net slip for different surcharges.

which is the facing net slip. The ratio of facing net slip to the critical depth for high and medium surcharges is 2.32 and 1.43 times the low surcharge, respectively. Figure 13 displays the excavation net rotation variations versus normalized net slip for different surcharges. Increasing the surcharge increases both the rotational and the transitional deformations. The increase in rotational and transitional deformations is almost the same in both modes but does not follow a linear relationship. It can be seen that, for the values below the curve, the excavation deformation will be mostly sliding, and for the values above the curve, the deformation will be mainly rotational.
According to Section 7 of the National Building Regulations of Iran (Iran Foundation Engineering Code) [24], the permissible range of rotation in the foundation for the structural failure limit is 0.004 to 0.0067 radians, the maximum value of which is 0.0067 radians. Accordingly, when the excavation is on the failure threshold, for a low surcharge, the maximum of facing net rotation is 8 times the allowable maximum value of the regulations, and for a high surcharge, it is 17.75 times the allowable maximum value of the regulations.

3.3. Ground Settlement on the Facing Fracture Threshold. Using the image processing method, one image was recorded exactly at the moment of start of excavation and the other image exactly at the moment of facing fracture, and these two images were compared with each other. The settlement profiles were obtained based on the displacement of silica aggregates relative to fixed benchmarks installed on plexiglass.

In the first test, which has no nailing or surcharge, the excavation failure begins with the start of excavation process, and as the excavation progresses, the failure wedges become larger. However, in the second, third, and fourth tests, where the excavations were stabilized by nailing, large deformations progression is much slower, and the deformations are also smaller, which means that nailing has a positive effect on reducing large deformations. As the excavation progresses, the facing under the soil pressure moves away from the soil, so a settlement occurs in the soil behind the facing. Figure 14 shows the ground surface settlement profiles that are under different surcharges. It can be seen that the settlement is differential, and the ground surface settlement profile on the facing fracture threshold is two-line or three-line so that the closer the excavation edge, the greater the amount of settlement. To calculate the settlement at the ground surface for each of the excavations by calculating the displaced soil volume, it can be seen that the higher the surcharge, the lower the soil settlement on the facing fracture threshold. For high surcharge $(100 \mathrm{kPa})$, the reduction of soil settlement is significant, which is due to the lower critical depth of excavation in this case. It also seems that there is an inverse relationship between the failure rate and the ground surface settlement amount, i.e., the higher the surcharge, the lower the critical depth, so the faster the model approaches the failure state, and the ground surface does not have the required opportunity to deform much; consequently, the ground settlement will be less at the moment of facing fracture. Tei et al. [18] performed centrifuge tests on $20 \mathrm{~cm}$ deep nailed excavations at $30 \mathrm{~g}$ acceleration in Leighton Buzzard dry sandy soil with a relative density of about $90 \%$ while the excavation was not under surcharge. It was observed that the settlement profiles are three-line and both the amount of settlement and the settlement increment rate increase by approaching the excavation edge, which is in good agreement with the results of the present study. Razavi and Hajialilu-Bonab [17] used a finite difference three-dimensional model to investigate nailed excavations with uniform nail length under service load. It was observed that, 


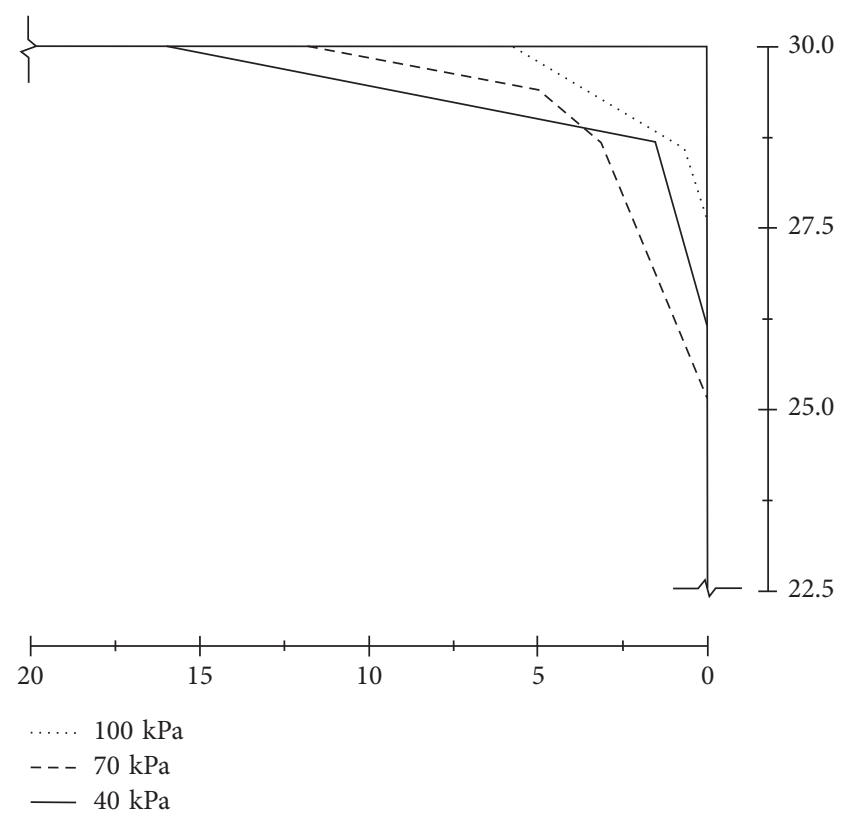

FIGURE 14: Ground settlement profile on the facing fracture threshold for different surcharges.

in clay soils, the settlement profile is almost multiline with a slight curvature, and the closer the excavation edge, the more the settlement becomes. However, for sandy soils, the settlement profile is curved, and most settlement is seen behind the nails. Sabermahani et al. [16] used centrifuge tests to evaluate the performance of nailed excavations under surcharge. The soil used was Firoozkooh sand with a relative density of $60 \%$, the excavation depth was $14 \mathrm{~cm}$, the target acceleration was $50 \mathrm{~g}$, and the length of the nails was uniform at $70 \%$ of the depth above the excavation. It was seen that the settlement profile is multiline, and the closer the excavation edge, the higher the settlement and the settlement rate. Jacobsz [22] also showed that the soil settlement profile is multiline (three or four lines) so that the closer the excavation edge, the higher the settlement and settlement rate.

\subsubsection{Minimum Allowable Distance of Foundation from the} Excavation Edge. If a structure is close to the excavation edge, the surcharge tends to destabilize the excavation. Engineering standards provide a minimum distance for the structure from the slope edge to avoid slope stimulation and the formation of failure wedges. In fact, this distance depends on the soil characteristics, surcharge amount, and excavation geometry. However, to make a thumb calculation independent of related parameters, the International Building Code (IBC) [25] for a vertical slope with depth $\mathrm{H}$ has proposed a minimum distance from the excavation edge equals to $1.33 \mathrm{H}$, while Iran Foundation Engineering Code [24] has conservatively suggested $2 \mathrm{H}$ (Figure 15). According to this research, if large settlements are the basis of the design, the maximum distance affected from the excavation edge is $0.53 \mathrm{H}$. But if the minimum distance is considered exactly behind the failure wedge, this distance varies in the range of $0.6 \mathrm{H}$ to $\mathrm{H}$, and the maximum distance is considered
H. It is possible to distance from the failure wedge to provide safety, so by applying the safety factor equal to 1.5 , the distance $1.5 \mathrm{H}$ seems reasonable.

3.3.2. Affected Distance. Excavation causes settlement on adjacent ground, but the question is how far from the excavation is affected by large settlements? According to FHWA-NHI-14-007 [26], for vertical nailed excavations in sandy soils, the affected distance is $1.25 \mathrm{H}(\mathrm{H}$ : excavation depth). It should be noted that this value is suggested with the assumption of accurate design and sufficient safety factor because despite sufficient safety, the deformations are smaller, but can affect a more extensive distance. Nevertheless, the present study results show that the affected distance is limited to a maximum of about $0.5 \mathrm{H}$ because with small nails length and insufficient safety factor, large deformations and, eventually, the failure will occur, which will lead to the concentration of deformations in the area under stress (failure wedge), and deformations will not be propagated further.

3.4. Facing Fracture Mechanism. According to Figure 16, in all three nailed excavations, the facing fracture is seen as a folding. It seems that the soil pressure behind the facing is applied as a resultant shear force and leads to its fracture at a depth called the facing folding depth. In other words, the folding depth is the resultant force depth of the soil behind the facing. It can be seen that the facing fracture is first accompanied by a fold in it so that due to the soil pressure, the failure wedge of the soil is formed behind the facing, and then, the facing is folded. In all three tests, the facing experiences folding, except that, at low and medium surcharges, folding occurs at a certain depth, but in an excavation under high surcharge, the facing folds diagonally. In this way, the effect point of shear force of soil that is applied to the facing can be investigated. For a low and medium surcharge, folding occurs at a constant depth, and the value of this depth is 22 and $19.6 \mathrm{~cm}$, respectively, while at a high surcharge, folding occurs diagonally and in the upper two-thirds of the facing, which can be due to the lower critical depth of this excavation because of its higher surcharge. The maximum folding depth for a high surcharge is $20 \mathrm{~cm}$. Thus, at medium and low surcharges, the folding depth is close to $2 \mathrm{H} / 3$, which is in accordance with the assumptions of the triangular pressure profile. In addition to folding and facing fracture, local fractures and cracks are also observed on the facing surface, which provides a good view of the facing fracture mechanism. For a high surcharge, a diagonal folding plays a dominant role, but for a medium surcharge, in addition to the facing folding and slurry baldness, two large diagonal fractures can be seen in the distance of $\mathrm{H} / 3$ to $\mathrm{H} / 6$ from the facing bottom, which indicates bending in this area. In an excavation that has been subjected to a low surcharge, in addition to folding, there are various small vertical, oblique, and horizontal fractures and facing baldness in some places. A summary of the test results is shown in Table 3. 


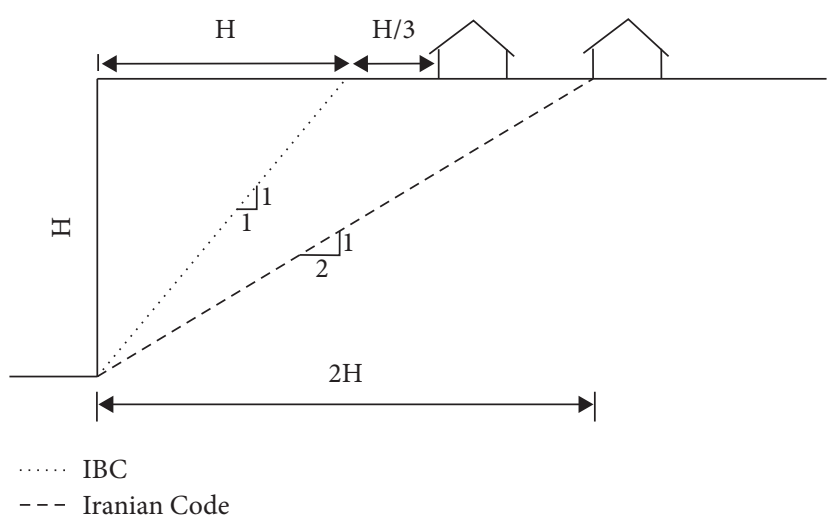

FIGURE 15: Minimum distance of foundation from the excavation edge according to IBC [25] and Iran Foundation Engineering Code [24].

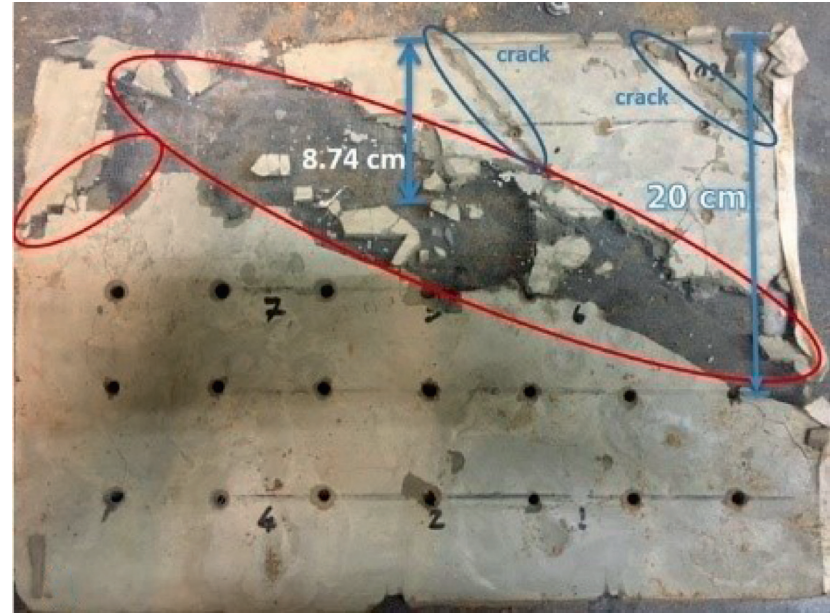

(a)

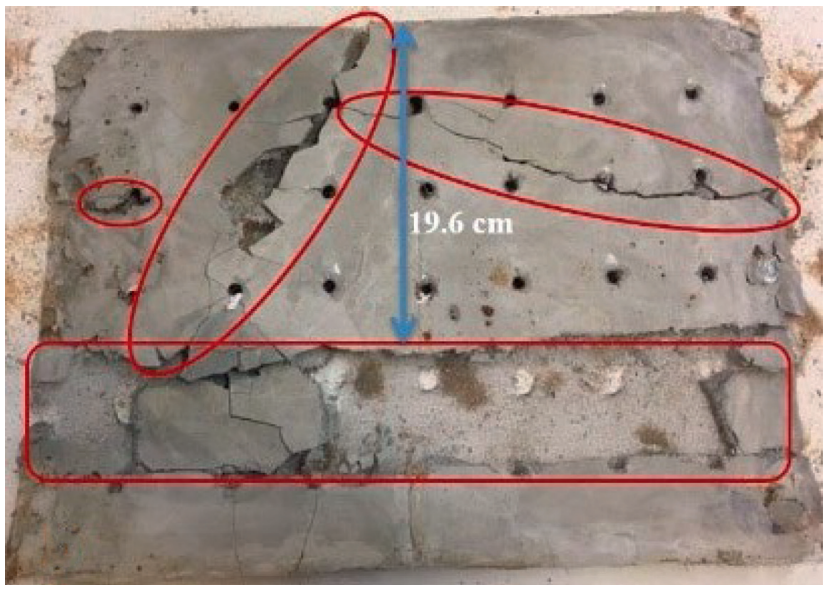

(b)

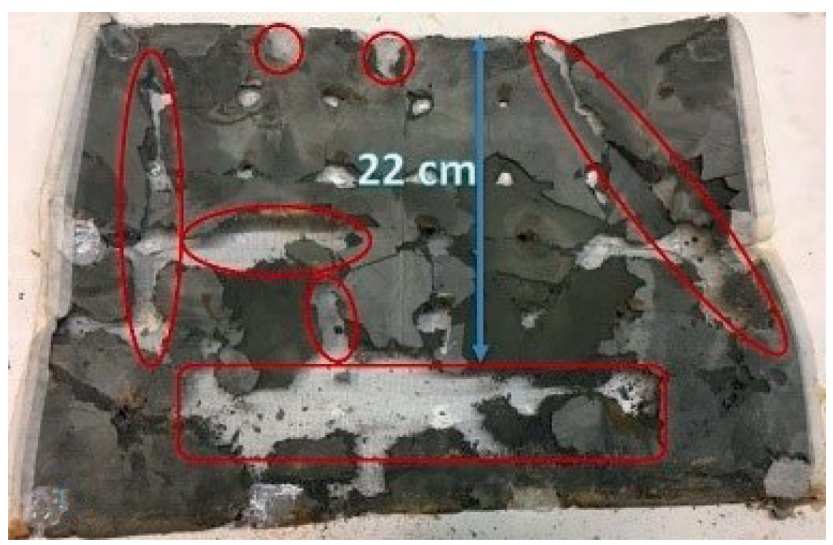

(c)

FIGURE 16: Facing fracture mechanism. (a) $100 \mathrm{kPa}$ surcharge. (b) $70 \mathrm{kPa}$ surcharge. (c) $40 \mathrm{kPa}$ surcharge.

TABLE 3: Summary of test results.

\begin{tabular}{|c|c|c|c|c|c|c|}
\hline Test no. & $q(\mathrm{kPa})$ & $h_{\mathrm{cr}}(\mathrm{cm})$ & $x(\mathrm{~cm})$ & $\Delta(\mathrm{cm})$ & $\theta(\mathrm{rad})$ & $\Delta / h_{\mathrm{cr}}$ \\
\hline 1 & 0 & 3.9 & - & - & - & - \\
\hline 2 & 100 & 12.9 & 0.53 & 1.7 & 0.071 & 0.118 \\
\hline 3 & 70 & 18.5 & 0.6 & 1.52 & 0.063 & 0.092 \\
\hline 4 & 40 & 21.7 & 0.43 & 1.13 & 0.032 & 0.052 \\
\hline
\end{tabular}

$q$ denotes surcharge, $h_{\mathrm{cr}}$ denotes critical depth, $x$ denotes slip of the facing at the excavation floor level, $\Delta$ denotes total lateral deformation of the facing, and $\theta$ denotes facing net rotation. 


\section{Conclusion}

In the present study, the nailed deep vertical excavation behaviour under surcharge was investigated by centrifuge at an acceleration of $40 \mathrm{~g}$, and the surcharge effect on the excavation performance was assessed. Based on the interpretation of centrifuge tests results, the following results can be obtained:

(a) Facing deformation on the fracture threshold includes a combination of transitional, bulging, and rotational movements. The amount of facing net rotation is directly related to the surcharge. The minimum and maximum rotation that causes the facing fracture is 0.032 and 0.071 radians. Also, the minimum and maximum displacement at the excavation floor level is 0.43 and $0.6 \mathrm{~cm}$ and at the top of the excavation is 1.13 and $1.7 \mathrm{~cm}$, respectively.

(b) An increase in surcharge increases the rotation and slip of the facing, but this increase does not follow a linear relationship. At a low surcharge, the failure rotation threshold is lower, and at a high surcharge, it is higher so that, at a high surcharge, it is 2.36 times the low surcharge. At the failure threshold and above the excavation, $0.052<\Delta / h_{\mathrm{cr}}<0.118$, so when the excavation is on the failure threshold, the excavation total rotation is 8 and 17.85 times the allowable rotation maximum of the foundation, respectively.

(c) Nailing reduces excavation settlement. The settlement profile in the excavations on the facing fracture threshold is two-line or three-line, and the closer the excavation edge, the higher the settlement. There is an inverse relationship between failure rate and ground surface settlement. The higher the surcharge, the lower the critical depth and the faster the model reaches failure, so the ground does not have the opportunity to experience much settlement.

(d) To observe the minimum distance from the excavation edge to prevent failure in the excavations, a minimum distance of $1.5 \mathrm{H}$ is recommended. Iran Foundation Engineering Code proposal seems to be conservative.

(e) At low and medium surcharges, the facing folding depth is about $2 \mathrm{H} / 3$ from the ground surface, but at a high surcharge, the facing fracture occurs diagonally. The maximum depth of facing fracture at a high surcharge is about $2 \mathrm{H} / 3$.

\section{Data Availability}

The data used to support the findings of this study are included within the article.

\section{Conflicts of Interest}

The authors declare that there are no conflicts of interest regarding the publication of this paper.

\section{Acknowledgments}

The authors would like to thank Physical Modelling Center of Tehran University for providing requirements for modelling and centrifuge testing. The project has received no financial support from any organization and all of the research expenses was on the first author.

\section{References}

[1] Clouterre FNRP, "Recommendations CLOTERRE 1991-soil nailing recommendations," Report no: FHWA-SA-93-026, FHWA, Virginia, MT, USA, 1991.

[2] E. Guler and C. F. Bozkurt, "The effect of upward nail inclination to the stability of soil nailed structures," Geotechnical Engineering for Transportation Projects, vol. 2, no. 126, 2004.

[3] M. Hajialilu-bonab and S. K. Razavi, "A study of soil-nailed wall behaviour at limit states," Ground Improvement, vol. 169, no. GI1, pp. 64-76, 2015.

[4] R. A. Jewell and M. J. Pedley, "Analysis for soil reinforcement with bending stiffness," Journal of Geotechnical Engineering, vol. 118, no. 10, pp. 1505-1528, 1992.

[5] Y. K. Shiu and G. W. K. Chang, Effects of Inclination, Length Pattern and Bending Stiffness of Soil Nails on Behaviour of Nailed Structures, The Government of the Hong Kong Special Administrative Region2006 Contract No: 197, Hong Kong, China, 2006.

[6] V. P. Singh and G. L. Sivakumar Babu, "2D numerical simulations of soil nail walls," Geotechnical \& Geological Engineering, vol. 28, no. 4, pp. 299-309, 2010.

[7] W. B. Wei and Y. M. Cheng, "Soil nailed slope by strength reduction and limit equilibrium methods," Computers and Geotechnics, vol. 37, no. 5, pp. 602-618, 2010.

[8] A. Askari and A. Gholami, "Effect of nail's orientation and length on soil-nailed retaining structures' stability," DFI Journal: the Journal of the Deep Foundations Institute, vol. 11, no. 1, pp. 30-38, 2017.

[9] C.-C. Fan and J.-H. Luo, "Numerical study on the optimum layout of soil-nailed slopes," Computers and Geotechnics, vol. 35, no. 4, pp. 585-599, 2008.

[10] V. M. Rotte and B. V. S. Viswanadham, "Influence of nail inclination and facing material type on soil-nailed slopes," Ground Improvement, vol. 166, no. GI2, pp. 86-107, 2013.

[11] H. Lin, W. Xiong, and P. Cao, "Stability of soil nailed slope using strength reduction method," European Journal of Environmental and Civil Engineering, vol. 17, no. 9, pp. 872-885, 2013.

[12] G. L. Sivakumar Babu, B. R. Srinivasa Murthy, and A. Srinivas, "Analysis of construction factors influencing the behaviour of soil-nailed earth retaining walls," Proceedings of the Institution of Civil Engineers - Ground Improvement, vol. 6, no. 3, pp. 137-143, 2002.

[13] M. Jayanandan and S. Chandrakaran, "Numerical simulation of soil nailed structures," International Journal of Engineering Research and Technology, vol. 4, no. 8, 2015.

[14] S. Ghareh, "Parametric assessment of soil-nailing retaining structures in cohesive and cohesionless soils," Measurement, vol. 73, pp. 341-351, 2015.

[15] A. M. Halabian, A. M. Sheikhbahaei, and S. H. Hashemolhosseini, "Three dimensional finite difference analysis of soil-nailed walls under static conditions," Geomechanics and Geoengineering, vol. 7, no. 3, pp. 183-196, 2012.

[16] M. Sabermahani, F. Ahimoghadam, and V. Ghalehnovi, "Effect of surcharge magnitude on soil-nailed wall behaviour 
in a geotechnical centrifuge," International Journal of Physical Modelling in Geotechnics, vol. 18, no. 5, pp. 225-239, 2018.

[17] S. K. Razavi and M. Hajialilu-bonab, "Study of soil nailed wall under service loading condition," Geotechnical Engineering for Transportation Projects, vol. 170, no. 2, pp. 1-14, 2016.

[18] K. Tei, R. N. Taylor, and G. W. E. Milligan, "Centrifuge model tests of nailed soil slopes," Soils and Foundations, vol. 38, no. 2, pp. 165-177, 1998.

[19] B. L. Kutter, "Dynamic centrifuge modeling of geotechnical structures," Transportation Research Record, vol. 1336, pp. 24-30, 1992.

[20] J. Zhang, J. Pu, M. Zhang, and T. Qiu, "Model tests by centrifuge of soil nail reinforcements," Journal of Testing and Evaluation, JTEVA, vol. 29, no. 4, pp. 315-328, 2001.

[21] M. D. Bolton and D. I. Stewart, "The response of nailed walls to the elimination of suction in clay," International Conference of Reinforced Soil, Strathclyde University, Glasgow, Scotland, 1990.

[22] S. W. Jacobsz, "Centrifuge modelling of a soil nail retaining wall," Journal of the South African Institution of Civil Engineers, vol. 55, no. 1, pp. 85-93, 2013.

[23] G. Vernagelte, Gelandesprunge-Tragverhalten und Standsichrheit, University of Karlsruhe, Karlsruhe, Germany, 1987.

[24] Office NBR, Section 7 (Iran Foundation Engineering Code), National Building Regulations Office, Tehran, Iran, 3 edition, 2014.

[25] Council IIC, International Building Code, ICC, New Delhi, India, 2018.

[26] FHWA-NHI-14-007, Soil Nail Walls, Reference Manual, FHWA, Virginia, MT, USA, 2015. 